九州大学学術情報リポジトリ

Kyushu University Institutional Repository

\title{
A COMBINATORIC PROBLEM SOLVED VIA ALGEBRA INTERPRETATION
}

Hirose, Hideo

Data Science Research Center, Hiroshima Institute of Technology

Takatou, Masanori

Department of Civil and Environmental Engineering, Hiroshima Institute of Technology

https://doi.org/10.5109/2233854

出版情報: Bulletin of informatics and cybernetics. 50, pp.15-17，2018-12. Research Association of Statistical Sciences

バージョン：

権利関係 : 


\section{A COMBINATORIC PROBLEM SOLVED VIA ALGEBRA INTERPRETATION}

by

Hideo Hirose and Masanori TaKatou

Reprinted from the Bulletin of Informatics and Cybernetics

Research Association of Statistical Sciences, Vol.50

FUKUOKA, JAPAN

2018 


\title{
A COMBINATORIC PROBLEM SOLVED VIA ALGEBRA INTERPRETATION
}

\author{
By
}

\author{
Hideo HiRose $^{*}$ and Masanori Takatou ${ }^{\dagger}$
}

\begin{abstract}
A problem that seems to be tough in a field sometimes becomes easy to solve by looking at it from a different field. In this note, a problem in combinatorics is framed as a problem in algebra, where it becomes easier to solve. The concept of algebraic proofs of non algebraic results is not mere mathematical curiosity but in some cases the proofs become remarkably easy.
\end{abstract}

Key Words and Phrases: combinatorics; counting the number of nonnegative integer solutions; algebraic proof.

\section{Introduction}

This paper gives a simple proof of the fact that the total number of possible solutions to

$$
x_{1}+x_{2}+\cdots+x_{n} \equiv k \quad(\bmod p)
$$

is $p^{n-1}$ for all $k \in\{0,1, \ldots, p-1\}$, where $x_{i} \in\{0,1, \ldots, p-1\}(i=1, \ldots, n)$.

For example, we consider the case of $p=3$, and $n=3$.

Elements of $\left(x_{1}, x_{2}, x_{3}\right)$ that satisfy $x_{1}+x_{2}+x_{3} \equiv 0(\bmod 3)$ are $\left(x_{1}, x_{2}, x_{3}\right)=$ $(0,0,0),(0,1,2),(0,2,1),(1,0,2),(1,1,1),(1,2,0),(2,0,1),(2,1,0),(2,2,2)$.

Elements of $\left(x_{1}, x_{2}, x_{3}\right)$ that satisfy $x_{1}+x_{2}+x_{3} \equiv 1(\bmod 3)$ are $\left(x_{1}, x_{2}, x_{3}\right)=$ $(0,0,1),(0,1,0),(0,2,2),(1,0,0),(1,1,2),(1,2,1),(2,0,2),(2,1,1),(2,2,0)$.

Elements of $\left(x_{1}, x_{2}, x_{3}\right)$ that satisfy $x_{1}+x_{2}+x_{3} \equiv 2(\bmod 3)$ are $\left(x_{1}, x_{2}, x_{3}\right)=$ $(0,0,2),(0,1,1),(0,2,0),(1,0,1),(1,1,0),(1,2,2),(2,0,0),(2,1,2),(2,2,1)$.

The number of solutions is $3^{3-1}=9$ in each case. It seems to be complex to write down all the cases for general $p, k$ and $n$.

Equation (1) is the same as

$$
x_{1}+x_{2}+\cdots+x_{n}=k+j p \quad(0 \leq j<n) .
$$

This may be applied to allocation problems with additional bonus under the restriction to each $x_{i}$.

In combinatorics, Equation (2) is regarded as an extension problem of the fundamental counting problem such that the total number of solutions in non-negative integers to

$$
x_{1}+x_{2}+\cdots+x_{n}=k
$$

\footnotetext{
* Data Science Research Center, Hiroshima Institute of Technology 2-1-1 Miyake, Saeki, Hiroshima 731-5193 Japan. tel +81-82-921-3121 h.hirose.tk@hiroshima-it.ac.jp

$\dagger$ Department of Civil and Environmental Engineering, Hiroshima Institute of Technology 2-1-1 Miyake, Saeki, Hiroshima 731-5193 Japan. tel +81-82-921-3121 m.takatoh.rd@cc.it-hiroshima.ac.jp
} 
is $\left(\begin{array}{c}n+k-1 \\ k\end{array}\right)$. The number of solutions for Equation (3) is easily derived by allocating $k-1$ wedges into $(n+k-1)$ places, i.e., $\left(\begin{array}{c}n+k-1 \\ k\end{array}\right)$. However, we cannot use such an ordinary method because $x_{i}$ is restricted such that $x_{i} \in\{0,1, \ldots, p-1\}(i=1, \ldots, n)$. A more general problem could be useful to find the total number of solutions in non-negative integers to $x_{1}+x_{2}+\cdots+x_{n}=k$, where, $0 \leq a_{i} \leq x_{i} \leq b_{i}(i=1, \ldots, n)$. This is equivalent to the problem of finding the total number of solutions in non-negative integers to $y_{1}+y_{2}+\cdots+y_{n}=k-s$, where, $0 \leq y_{i} \leq b_{i}-a_{i}, s=\sum_{i=1}^{n} a_{i}$.

To obtain the solution for Equation (3), we often use the inclusion-exclusion principle, and the following formula is useful.

$$
\left|A_{1} \cup \cdots \cup A_{n}\right|=\sum_{\emptyset \neq I \subseteq\{1, \ldots, n\}}(-1)^{|I|+1}\left|\cap_{i \in I} A_{i}\right|,
$$

where $|\cdot|$ denotes the number of elements in a set. The method using the inclusionexclusion principle seems to be complex and awkward. The raised problem seems to be tough via the combinatorics methods.

However, the solution is easily solved if the problem is interpreted as a problem in algebra.

\section{Algebraic Problem}

Theorem 2.1 Algebra. Let $n$ and $p$ be integers with $n \geq 1$ and $p \geq 2$. Define $X=\left\{x=\left(x_{1}, x_{2}, \ldots, x_{n}\right) \mid 0 \leq x_{i} \leq p-1, x_{i} \in \mathbb{Z}, 1 \leq i \leq n\right\}$. For $x, y \in X$, we define $x \sim y \Leftrightarrow \sum_{i=1}^{n} x_{i} \equiv \sum_{i=1}^{n} y_{i}(\bmod p)$, Then, “ " constitutes an equivalence relation. We set $X / \sim=\left\{C_{0}, C_{1}, \ldots, C_{p-1}\right\}$, where $C_{j}=\left\{x \in X \mid \sum_{i=1}^{n} x_{i} \equiv j(\bmod p)\right\}$. Then, the number of elements in $C_{0}$ is the same as that in $C_{j}$, i.e., $\left|C_{0}\right|=\left|C_{j}\right|=p^{n-1}(1 \leq$ $j \leq p-1)$.

Proof. For $x=\left(x_{1}, x_{2}, \ldots, x_{n}\right), y=\left(y_{1}, y_{2}, \ldots, y_{n}\right) \in X$, we define an addition $\oplus$ on $X$ by $x \oplus y=\left(\left(x_{1}+y_{1}\right) \bmod p,\left(x_{2}+y_{2}\right) \bmod p, \ldots,\left(x_{n}+y_{n}\right) \bmod p\right)$, where $\left(x_{i}+y_{i}\right) \bmod p$ is the remainder obtained by dividing $x_{i}+y_{i}$ by $p$ for each $i$ with $1 \leq i \leq n$. Let $j$ be an integer with $0 \leq j \leq p-1$, and let $a=(j, 0,0, \ldots, 0) \in C_{j}$. For $x \in C_{0}$, we can define $f: C_{0} \rightarrow C_{j}$ by $f(x)=x \oplus a$. Then $f$ is a bijection, and hence we have $\left|C_{0}\right|=\left|C_{j}\right|$. Since $j$ is arbitrary, we obtain $p^{n}=|X|=\left|C_{0}\right|+\left|C_{1}\right|+\cdots+\left|C_{p-1}\right|=p\left|C_{0}\right|$, and therefore $\left|C_{0}\right|=\left|C_{1}\right|=\left|C_{2}\right|=\cdots=\left|C_{p-1}\right|=p^{n-1}$.

From this, we can easily derive the next theorem.

\section{Combinatoric Problem}

To interpret the algebraic problem to the combinatoric problem, we only regard $x_{i} \in\{0,1, \ldots, p-1\},(i=1, \ldots, n)$ in equation (1). This delivers the answer to the combinatoric problem.

Theorem 3.1 Combinatorics. The solution to the number of cases that $x=$ $\left(x_{1}, x_{2}, \ldots, x_{n}\right)$ satisfies Equation (1) is $p^{n-1}$ for all the cases $k=0,1, \ldots, p-1$.

Proof. Direct interpretation to Theorem 1 (Algebra). 
Received May 15, 2018

Revised August 6, 2018 